The Ideology of Silence at the Harvard Business School:

Structuring Faculty's Teaching Tasks for Moral Relativism

\author{
Michel Anteby* \\ Boston University
}

- August 18, 2015 -

Prepared for Research in the Sociology of Organizations: The Structure of Work in Organizations eds. Diane Burton, Lisa Cohen, and Michael Lounsbury.

Word count target: 7,530 (with Table and references)

Acknowledgments: I am extremely grateful to Gabriel Abend, Lisa Cohen, Siobhan O’Mahony, Kelley Packalen, and Victor Seidel for their comments on previous drafts of this article.

* Please direct all correspondence to: Michel Anteby, Associate Professor of Organizational Behavior, Boston University, 595 Commonwealth Avenue, Boston, MA 02215 USA / Email: manteby@bu.edu 


\title{
An Ideology of Silence at Harvard Business School: Structuring Faculty's Teaching Tasks for Moral Relativism
}

\begin{abstract}
:
Business schools offer a unique window into the making of corporate morals since they bring together future executives at formative moments in their professional lives. And business school faculty members play a crucial role in shaping these morals. This article relies on an analysis of faculty members' teaching tasks at the Harvard Business School to better understand the making of corporate morals. More specifically, it builds on a coding of teaching notes used by faculty in the first-year MBA curriculum to highlight the importance of silence in promoting a culture of moral relativism. Indeed, while notes heavily script faculty's teaching tasks and cast business decisions as matters of individual choice, they also remain silent on the moral compass that might guide these choices; allowing for moral relativism to prevail. Put otherwise, faculty's teaching tasks are structured to refrain from passing judgment on any given moral viewpoints. In doing so, a form of moral relativism is promoted. The ideology of silence that guides and gets reflected in faculty's teaching tasks, constitutes, I argue, a powerful ideology—one that implicitly primes business leaders not to vilify any moral stand, but also justifies a very wide range of stands. In this context, almost anything can be labeled "moral" and few behaviors can be deemed "immoral."
\end{abstract}

Word count: 212 


\section{Introduction}

As our recent history suggests, business leaders are rarely held individually accountable for any wrongdoings uncovered under their leadership. Whether the wrongdoings involve disastrous decisions made by General Motors executives after learning about faulty ignition switches in Chevrolet Cobalt vehicles, or misleading accounting practices used by Lehman Brothers' executives to temporarily remove securities from the company's balance sheet and mask financial losses, very few business leaders seem to be stigmatized by their peers for their misguided behavior. While stealing eggs in a supermarket might label you immoral, causing deaths on roads or depleting the life-savings of pensioners will barely dent your career. Why is it the case that business leaders are rarely held morally responsible for their actions? My argument is that the ways they get socialized to take on business responsibilities might in part explain this puzzle. In this article, I suggest that these leaders' socialization in business schools might lay the ground for this collectively constructed inability to hold anyone accountable for his or her dubious moral choices. More specifically, the moral silence that many of these leaders encounter in business school classrooms might plant the seeds for this state of affairs. Making such an argument requires, however, bringing faculty members' work back into the equation (Barley \& Kunda, 2001), particularly by looking at the structuring of their teaching tasks in business schools.

From a sociological perspective, morals are often conceptualized as cultural constructions (e.g., Lamont, 2010; Zelizer, 1979): ones produced inside institutions that include families and faith communities, but also educational settings. Like proper dining habits (Parkhurst Ferguson, 2004), morals are an acquired taste. Since many business leaders get trained in business schools, it makes sense to focus our attention on the inner working of such institutions (Hallett \& 
Ventresca, 2006). Moreover, given that faculty members play a crucial role in students' education, paying close attention to the ways faculty members' teaching tasks are structured provides cues to these institutions' cultural underpinnings. In a sense, the tasks being performed at work (L. E. Cohen, 2013) and the micro negotiated orders that emerge from them (Fine, 1984) are key windows into broader cultural constructions.

This article builds on a larger ethnography of faculty socialization at the Harvard Business School (Anteby, 2013) and relies on an analysis of faculty members' teaching tasks to better understand how certain morals get produced. I show, in particular, how the faculty members' teaching tasks are structured to uphold moral silence and to refrain from passing judgment on any students' moral viewpoints. By upholding silence, the organization tries to withhold direct guidance on given moral topics. (Here, silence is defined from an organizational viewpoint, not that of a member. $)^{1}$ In fostering such behavior, a form of moral relativism gets promoted (Abend, 2014); one that might explain part of our collectively constructed inability to hold business leaders and executives morally accountable for their actions. Thus, my point in this article is to document a potential mechanism (i.e., silence) that supports moral relativism among business leaders. I present, below, the setting of my argument, the data and methods employed, key findings from the analysis, and their implications for business morals.

\section{Setting: The Work of the Harvard Business School Faculty}

What is currently at stake at several leading U.S. business schools is the socialization into a new worldview, not merely the acquisition of technical skills (Abend, 2013, 2014; Gehman, Treviño, \& Garud, 2013; Khurana, 2007). The education offered by these schools' faculty members taps into what students want to become and involves a socialization process into a new or, at least, a

\footnotetext{
${ }^{1}$ For a discussion of silence from members' perspective, see Morrison and Milliken (2000).
} 
newly salient institutional perspective (Petriglieri \& Petriglieri, 2010)—one that, I argue, is eminently "moral" in nature. While not all U.S. business schools embrace such goals or are as explicit about it as the one I studied, the moral trope is probably more prominent at the schools that Debra Schleef (2006) describes as "high-ranked" or elite schools. Indeed, the skill set taught in many elite U.S. business schools, including the Harvard Business School, would be limited were it not for its social component (namely, the development of soft skills and a social network, but also the learning of proper business conduct). If technical skills alone were being taught, a vocational school could (and historically did) easily supplant today's elite university-affiliated business schools (Khurana, 2007; Ruef, 2008). Regardless of one's assessment of the actual outcomes of business schools' pursuits, the stated desire for higher goals is what set many of these elite business schools apart from alternate educational venues.

The historical milieu from which business schools emerged - U.S. society in the nineteenth century — generated in part the moral imperative found in many elite U.S. business schools today. As Charles Perrow (2002, p. 220) explains, "The [U.S.] manufacturing elite that was emerging [in the nineteenth century] was a motley bunch" that included gentlemen with landed wealth and wealthy merchants, but also farmers, small businessmen, and craftsmen. "Indeed, the emerging elite could be almost anything, as long as they were white and not Irish." As Perrow concludes, "There were few established traditions that might be blindly followed." In that context, an aspirational socialization project on the part of the emerging elite was hardly surprising. Thus, the emergence of elite U.S. university-based business schools can be viewed a socialization endeavor or even a "civilizing" project in the sense that Norbert Elias $(1983,2000)$ has employed the term to characterize undertakings that promote selected behaviors. 
The mandate of these business schools, in other words, was to teach not merely how to run a business, but also how a business should be run. This moral imperative of elite business schools was endorsed by many early figures central to university-based business education. The Harvard Business School's first dean embraced such a view and defined business as the "activity of making things to sell at a profit-decently" (Cruikshank, 1987, p. 44). The use of the term "decently" underlined his hope for developing a heightened sense of responsibility among businessmen. Similarly, the School's second dean viewed the development, strengthening, and multiplication of "socially minded businessmen" as a central goal of business education (Donham, 1927, p. 406). Such an aspiration also became the goal of other business schools. Elite business schools found a language to explain and justify their pursuit.

The establishment of the Harvard Graduate School of Business was true to this spirit. In 1908, Harvard University's president justified the decision to launch the venture by noting that "business in its upper walks has become a highly intellectual calling” (Khurana, 2007, p. 114). The invocation of a calling attributes a sacred nature to the endeavor. A calling also lends not only personal but also societal significance to students' future work. Other evidence confirms the framing of business education as a sacred, almost religious, path, likening businessmen to ministers. At the dedication of the School's new campus in 1927, the chairman of General Electric predicted that the Harvard Graduate School of Business "will do its utmost to guard against an illiterate ministry of business when our present ministers shall lie in the dust" (Khurana, 2007, p. 118). Clear links were being drawn between the School's goals and morals. Repeatedly over the School's history, the moral project was reiterated. At the School's founding, Harvard University's president explained that, given the enormous growth of the business sector, "a definite forward step" had to be made "in sustaining the ethical standards [of 
business]" (Cruikshank, 1987, p. 106). The School's first great benefactor, George F. Baker, president of the First National Bank, was also quite explicit about his overarching goal. "My life has been given to business," Baker explained in 1924, "and I should like to found the first Graduate School to give a new start to better business standards" [George F. Baker cited by Donham (1926, p. 122)]. With time the School's goals broadened, but the moral imperative remained prominent. In 1963, for instance, the School's catalogue listed "character" and "integrity" as qualities of a "good administrator" (Orth, 1963, p. 48). ${ }^{2}$ More recently, in 1992, the School's dean quoted an alumnus's disappointment "at how frequently the graduates of some of our finest business and law students were involved, in one way or another, in the cases being brought before the SEC [Securities and Exchange Commission]." The dean invoked this observation to support his conclusion that "Surely the school had a bigger responsibility and a role to play in all of this." [John MacArthur's foreword in Piper, Gentile, and Parks (1993, pp. xxiii)]. ${ }^{3}$ By bigger responsibility, he was referring to the School's role in developing business leaders' responsibility towards society.

Business leaders' responsibilities, and implicitly their moralities, have long attracted scholarly attention (Davis, 2009; Jackall, 1988; Margolis, 2001; Margolis \& Walsh, 2003; Morrill, 1991), but in the specific context of my study, no one perhaps more than the Harvard Business School's faculty members carry the burden of educating future business leaders and sensitizing, if not shaping, students' sense of responsibility. And nowhere are the faculty members' efforts more visible than in the case-teaching methodology, since case-teaching is

\footnotetext{
${ }^{2}$ The other qualities of a good administrator were flexibility, courage, imagination, initiative, and perseverance.

${ }^{3}$ These citations are from the foreword to a book on ethics published by the School. The book's first chapter, by Thomas R. Piper, also reiterates the School's moral imperative. See (Piper, et al., 1993, pp. x-xiii). A few years earlier, in 1985, McArthur also wrote that School faculty members were "committed to pursuing research on the way business actually does function, as well as theoretical explorations of how it perhaps should function." See (McArthur, 1985, p. vii).
} 
often viewed as the core of the School's educational model and the motor for developing students' moral compass (Barnes, Christensen, \& Hansen, 1994; Christensen, Garvin, \& Sweet, 1991). As a senior School faculty member remarks, "teaching is a moral act" (Christensen et al., 1991, p. 117) and cases are the vessels through which student learn to develop their moral judgment. This explains why I decided to look into these cases, and more specifically into the teaching notes that accompany them. The rationale for my examining notes is that if a moral trope exists, it should be reflected in these organizational artifacts. As my analysis will suggest, these notes structure faculty members' teaching tasks in very direct ways, and studying these tasks helps decipher the School's broader moral pursuit.

\section{Data and Methods}

Teaching notes are typically ten- to fifteen-page documents, available to School faculty members and registered instructors elsewhere, that provide precise and meticulous guidance on how to conduct a classroom session on a given case. The faculty member who developed and first taught the case usually writes its teaching note. Organizational artifacts like these notes can be very consequential (Carlile, 2004). Like a trail or a sky map, a teaching note provides a lens through which to see, read, and navigate the case data, as well as act as an "exemplar" of how the teaching session might proceed (Boltanski \& Chiapello, 1999; Both, 2008). Alongside teaching group meetings held at the School that bring together all faculty teaching a given course, notes are the bedrock of a faculty member's preparation and prized tools to disseminate the School's viewpoint to others instructors worldwide. They are rich documents that capture the accumulated experience of various instructors who have taught the case and familiarize other instructors with the case's various usages. Most junior faculty members at the School learn the tricks of their new 
trade by using these notes in conjunction with discussions with senior colleagues. Though not mandatory, notes tend to be carefully read and used, at least initially, by junior faculty members. The notes not only teach how to teach, but also ensure consistency in delivery across sections in any given course. (A first-year MBA cohort usually encompasses ten sections of approximately 90 students.) Teaching notes can thus act as powerful socialization tools for junior faculty members, and by extension for students, as well as guarantee a form of unity (almost regardless of instructors) throughout classrooms. ${ }^{4}$

So what do these notes tell us about the structure of faculty members' work, and more broadly about the organization's broader pursuit? In order to answer this question, I read and coded a sample of sixty-one notes used during the required first-year MBA curriculum. More precisely, I randomly selected one-third of all the notes available for each of the ten traditional required first-year MBA courses offered during the 2007-2008 academic year (fall 2007 and spring 2008). The courses included, for example, accounting, finance, and marketing offerings. See Table 1 for details on the sampling strategy. The sampled notes were coded in accordance with grounded theory guidelines (Glaser \& Strauss, 1967). An independent coder was also enrolled to perform a separate coding and discrepancies were resolved through discussion. Only the most common codes are reported here. I explain below how these notes aimed to heavily script faculty members' teaching tasks, how they cast business decisions as individual choice, yet how they remained silent on the moral compass that might guide these choices; allowing for moral relativism to prevail.

- Insert Table 1 approximately here -

\footnotetext{
${ }^{4}$ Many School courses also offer "course notes" and/or "module notes" (notes on a subset of class sessions) that summarize classroom presentation of all or part of a course at a more aggregate level. But new instructors' initial focus on day-to-day delivery of sessions guarantees that teaching notes play a more central role in getting up to speed on new courses.
} 


\section{Faculty Members' Scripted Teaching Tasks}

What do teaching notes help achieve? First, teaching notes help start a class discussion. For example, a note explains that "Instructors should open the class by asking a student: 'As an equity investor with a long-term horizon, what grade-A, B, C, etc. — would you give the firm's senior executive team for their performance?' Next, poll the students for their grades, based on a show of hands. Expect very few As and most likely an even distribution of Bs, Cs, and D/Fs."5 Instructors who rely on such an opening are likely to initiate discussion on a strong footing: immediately forcing students to take a stand is a proven route of entry into a case. Moreover, such an initial overture also pushes students to justify their assessments, at least in their own minds. Many variations on the assessment entry question populate the teaching notes: "On a scale from 1 to 10 , how would you assess the firm's performance?" "If given the opportunity, would you want to work for this company?" These variations also illustrate the numerous guiding questions found in the notes.

Second, teaching notes help structure the way faculty members deliver a session. The vast majority of teaching notes for first-year MBA courses (72 percent of the 61 sampled notes used in all ten required first-year courses) contain guiding questions that instructors can rely on at critical junctures to advance discussion. For example, an instructor who wants to shift the focus of classroom discussion from what's happening inside a company to external dynamics might ask, "Who buys these products anyway?" or "Who are the company's customers? Should we care about them?" Such questions help redirect students' focus from one topic to another. They also draw on the transitions that have worked best in the past, and as such offer scripts for

\footnotetext{
5. Because notes are available only to School instructors and other registered educators, the case contexts in these and other illustrations of typical case material have been disguised.
} 
successful teaching sessions. Much effort also goes into honing a precise wording that unambiguously draws attention to an unexplored tension or encourages a transition to a different subject of conversation. It is often said that skilled instructors who are already familiar with a given case can walk into the classroom with nothing more than the three or four main questions spelled out on a sheet of paper (or memorized) and lead a class discussion successfully on that basis alone.

New and less talented instructors, and certainly many junior faculty members, generally welcome more help. This is why most teaching notes (62 percent of sampled notes across all ten courses) also include typical student answers. As an illustration, the author of one note explains that, when probed about their assessment of a case protagonist, "many students, if not most, will see him as a sincere and well-intentioned human being. He has strong convictions (perhaps too strong), pride (perhaps too much), and compassion (perhaps too blinding). . . A few students, however, may contend that he is a bit of an egotist and perhaps even a bully." Armed with these insights, instructors can prepare themselves for possible scenarios that might occur in the classroom.

Though teaching sessions invariably differ, knowing typical reactions to given topics still proves handy. As another note's author, perhaps a bit blasé, remarks when referring to a case's action plan: "Students' answers are predictable: the largest numbers of students recommend some form of slap on the wrist and a smaller number recommend the outright firing of the protagonist. ... Few of the students choose to do nothing. . . There is a small but vocal group, however, that sees this as a watershed opportunity to 'walk the talk' on this question." The note encourages the instructor to spot and engage fairly rapidly with the vocal group, and possibly to rely on them to push back against the majority position. Notes never identify specific students, 
but students' pervasive generic presence in the notes' narratives vividly prepares instructors for the likely tenor of the classroom.

Third, teaching notes assist instructors in getting back on track when the teaching plan is derailed. Despite teaching notes' specification of guiding questions and typical student answers, classroom discussions often go off track. Small details in cases can easily spiral into full-blown debates. A protagonist's clothing, visible in a video, might lead to a discussion of power relations at work. The case's geographical setting could trigger debates about the pros and cons of urban renewal. A footnote in the appendix might even prompt a discussion of data validity. How to regain at least partial control of a class discussion, as sometimes proves necessary, is another common theme in teaching notes (present in 67 percent of sampled notes across all ten courses). Case-method purists might praise partial losses of control as providing ideal learning opportunities for insight to emerge from conversations. But in practice, few junior faculty members feel at ease teaching a case without some guiding compass in mind. Teaching notes are written to assuage their fears by offering concrete ways to regain control of off-track or stalled discussions. ${ }^{6}$

Similarly, when complex financial calculations pose a risk that ill-prepared students will slow down a session, another author suggests, "The calculations in the case are potentially quite complicated. To navigate through them smoothly, instructors may want to ask several student volunteers to submit their analyses the night before class. The instructor can then select a couple of students who have done the analysis well to lead the discussion. This reduces the risk that the class will get bogged down."

\footnotetext{
${ }^{6}$ For example, one note, whose author was once presumably caught off guard, advises, "If sentiment turns sharply negative, consider arresting the trend by saying: 'Wow: you guys are harsh graders! Let me remind you that this management team spotted these opportunities when the industry was not even formed. They built a business pretty much out of thin air. How could they be bad at what they do?"' Questions like this inevitably lead students back to consideration of the central issues of the case.
} 
Overall, the vast majority of teaching notes help jumpstart a discussion, redirect it during the flow of a class session, and point out landmines specific to the case in question and suggest pretested remedies to avoid or disable them. Like in other routinized work settings (M. D. Cohen \& Bacdayan, 1994; Leidner, 1993), teaching routines, like the one articulated via notes, can strongly structure employees' work. Not everybody follows the spelled-out routines, but most faculty members (particularly junior ones) seem to eagerly do so. Notes thus can serve as a "frame" and even "cultural anchors" or "handles" that allow for consistency in teaching (Benford \& Snow, 2000; Ghaziani \& Baldassarri, 2011; Goffman, 1974). While teaching notes specify clear methods and patterns with respect to the teaching process (namely guiding questions, typical answers, and techniques for regaining control), their combined and broader educational purpose proves, as I suggest next, less easy to pinpoint.

\section{High-Stakes (but Unspecified) Battles}

In School classrooms, teaching notes transform the often-complex flow of business life into a series of objectified and diverse business challenges. Like the training of medical students, which favors seeing reality through the lens of symptoms, diagnostics, and treatment, the training of business students - as articulated in most teaching notes - encourages a view of corporate life as a succession of challenges that demand varied and tested resolutions. ${ }^{7}$ By focusing on analytical tools designed to overcome challenges, the notes offer a rich repertoire that students can be expected to master. Via models, frameworks, and checklists, students gradually acquire technical breadth. The notes' stated goals in turn concentrate on ways to handle specific challenges. Thus

\footnotetext{
7. For a discussion of how medical education constructs its objects, see Byron J. Good, Medicine, Rationality and Experience: An Anthropological Perspective (Cambridge, UK: Cambridge University Press, 1994).
} 
the overlap between different teaching notes' stated goals is quite limited. Indeed, little broader purpose can be gleaned from surveying those goals.

Three-quarters of all notes ( 75 percent of sampled notes across all ten courses) articulate specific teaching or learning objectives; typical examples are providing "an opportunity for students to make a capital budgeting decision," understanding "the role of an occupation in an employee's life," considering "the legal tools available to create and capture value from innovation," and realizing that "markets go through stages of growth." Yet by focusing on discrete challenges in business life, the notes (and the cases they accompany) promote attainment of a set of skills in the service of a broader but also largely unspecified edifice or goal.

The stakes and significance of that broader purpose are nonetheless repeatedly emphasized. If cases are not about life and death, they are certainly about winners and losers in a challenging mêlée; the majority of notes include narratives that refer explicitly to the firms' or the protagonists' success and/or failure (69 percent of sampled notes across all ten courses). Success comes in many flavors and can be measured at many levels: most notably that of the protagonist (e.g., "The manager figured out how to operate in Asia, successfully adjusted his firm's business model, and is now poised for considerable success"), but also that of the workgroup (e.g., the chosen design "typically leads to improved worker morale and dedication, contributing to fewer worker grievances, lower worker absenteeism, and lower worker turnover") and the firm (e.g., "The product then achieved national distribution and several of the competitors mentioned in the case decided not to enter this market"). ${ }^{8}$

Perhaps more importantly, business life is depicted as offering simultaneous opportunities and pitfalls. A substantial number of notes point out that the situation in question can result in either failure or success (40 percent of all sampled notes, but spanning only nine courses),

\footnotetext{
${ }^{8}$ Failures are similarly described at all levels of analysis.
} 
underscoring that the course of action is by no means predetermined. The notes also prompt instructors and students to ponder the possible consequences of choices not made and paths not taken-always implicitly questioning whether the outcome might somehow have been different. In other words, notes assume a high level of individual agency. Case protagonists are participants in dramas in which confrontation with personal choice is the norm and carries heavy consequences.

Warlike terminology permeates several notes (18 percent of all sampled notes, but spanning only five courses), further underlining how high the stakes are in protagonists' environments. The parallels between this terminology and the unsecure "liquidated" culture favored by Wall Street investment bankers are numerous (Ho, 2009). In notes, companies “attack" markets, “declare fights" against other firms, and "engage in economic wars." At the same time, competitors in both local and global encounters are labeled "attackers," wrong moves are deemed "deal killers," and firms are described as vulnerable to "hostile takeovers." Some authors even suggest asking students questions like "What have been the 'weapons of war'?” and "How should the protagonist fight for survival?" In such unstable environments, clearly, no one is completely safe. Anybody can end up liquidated. Even the most storied companies can be brought down. Commenting on the "classic" quality of a studied case, an author explains that it exemplifies the situation of "historically successful companies that start to suffer performance pressures and appear (deceptively) to experience rebounds." Instructors reading the note understand that a battle is brewing, even if the case protagonists remain oblivious to what is to come. Between wins and losses, there is a battle in the making and its stakes are evident.

Another certainty is that the individual protagonists unmistakably lead these fights. In the same way that U.S. corporations tend to position managers as agents of change, many notes 
depict protagonists as almost heroic figures. ${ }^{9}$ Though success and failure are measured at multiple levels, such as winning promotions or increasing return on investment, teaching notes typically depict action as driven mainly by a solo protagonist (62 percent of sampled notes across all ten courses), not by teams or groups. ${ }^{10}$ Battles tend to be characterized as individual, and the implicit hope is that students will identify with the heroic protagonists. A significant number of notes (39 percent of sampled notes, spanning eight courses) suggest asking students to slide into the shoes of case protagonists. Two, for example, offer the following questions for the classroom: "Imagine you have oversight on this part of the business. Are you comfortable with what's going on?" and "Do you want to be in a position that your firm is the subject of such a story in the Wall Street Journal?" Implicitly, organizational outcomes can be traced to personal decisions. By placing the individual at center stage, teaching notes also suggest that protagonists can guide their own destinies. This view of leaders as crafters of their own fortunes reflects a broader U.S. managerial culture that favors what Katherine S. Newman has called "meritocratic individualism," defined as "the notion that individuals are responsible for their own destinies" (Newman, 1988, p. 75). Such an ontology transforms business outcomes into the result of individual struggles. Managers become part of a broader entrepreneurial group in which individualism and heroism prevail (Ruef, 2010). Structural social constraints are often overlooked in favor of a conceptualization of the world as composed of individual possibilities. But what guides individuals' decisions to opt for one or another possibility? The notes offer little moral guidance on this issue.

\footnotetext{
9. For examples of corporations promoting a view of managers as agents of change, see Vicky Smith, Managing in the Corporate Interest: Control and Resistance in an American Bank (Berkeley: University of California Press, 1990), 82; Nicole Woolsey Biggart, Charismatic Capitalism: Direct Selling Organizations in America (Chicago: University of Chicago Press, 1989), 105-6.

${ }^{10}$ The individual trope agency bias has been well documented across many business schools (Ghoshal, 2005).
} 


\section{Upholding Moral Relativism via Silence}

While teaching notes offer suggestions about how to teach a case, they mostly refrain from specifying what guides individuals' decisions. The notes script the teaching process to a certain point but typically leave unscripted the broader goals. Indeed, many, though not all, School students seem to aspire to engagement with something more than the mastery of technical tools to promote their individual advancement. Teaching notes occasionally allude to such broader goals (e.g., creating jobs, bolstering a country's competitiveness, and the like). But the articulation of such social goals is mostly left to the imaginations of faculty members and students. Teaching notes essentially refrain from scripting such goals; almost by design, they allow multiple goals to coexist. This relatively hands-off stance leaves classroom participants with the option, if exercised, to fill the gap.

This desire to accommodate multiple moral viewpoints has been apparent throughout the School's history. For example, Charles Gragg, a faculty member who authored a 1940 teaching note "Because Wisdom Can't Be Told," explained that "the principal object of professional education is to accelerate a student's ability to act in a mature fashion under conditions of responsibility" (Gragg, 1940, pp. 3-5). What constituted a mature fashion was purposely left unspecified. Gragg added that "each student is free to present and hold to his own views." This implicit moral relativism is also captured by James Bugental (1978) in his article "The Silence of the Sky," which used to be distributed to Harvard Business School students in a second-year elective course. ${ }^{11}$ Bugental wrote, "We look upon the world with questing eyes that search for meaning, and we are turned back upon our questions with no answers. We seek in vain for the

\footnotetext{
${ }^{11}$ The elective course was known as "interpersonal behavior."
} 
value, the virtue, the cause that is ultimate.... And still the sky is silent." No moral norm seems to prevail. With respect to moral decision making, faculty members involved in the School's formal ethics course offerings seem to agree with Gragg: they note that managers' actions need to "be guided and consistent with relevant ethical standards" or to meet "relevant" ethical “requirements," but steer clear of specifying what those standards or requirements are (Paine, 2006, p. 5; Sucher, 2011, p. 3). Another teaching note posits that managers' actions build on "personal, family, and cultural values, tenets of our religious beliefs and personal philosophies, past experiences, prior knowledge, and general understanding of what morality means," but again steers clear of articulating what such morals might entail (Sucher \& Hsieh, 2011, p. 1). Put otherwise, teaching notes define morality as accommodating many viewpoints. For all business leaders to coalesce under a tent, its size needs to be sufficiently large. Notes go beyond the mere promotion of moral pluralism. They also convey a sense of moral relativism. ${ }^{12}$

That the teaching notes refrain from emphasizing one set of morals versus another does not mean that judgment is absent from these organizational artifacts. Over half of all the notes analyzed depict individual protagonists' actions as either correct or wrong (56 percent of sampled notes across all ten courses). Yet judgment is largely reserved for the process. When the protagonist is presented as following a correct course of action, note authors tend to stress that he or she followed the appropriate steps. For example, one typical note author comments positively on the fact that a manager consulted with his client before deciding to modify the nature of the longstanding relationship between his firm and the client's. Similarly, another author remarks with approval that the protagonist not only pursued legal action against a competitor but also

\footnotetext{
${ }^{12}$ Moral pluralism and relativism share the assumption that multiple moralities can coexist, but moral pluralism differs from moral relativism since the former suggests multiple moralities should coexist, whereas the later implies that several moralities can prove equally justified.
} 
tried to explore all other possible parallel actions, and goes on to praise the protagonist's ability to analyze all of his options.

By contrast, protagonists depicted as taking wrong turns usually ignore an important market signal, disregard vital information conveyed to them, or underestimate workforce inertia. In the unraveling dramas that ensue, they overlook key warnings signs. Though these notes' narratives convey some normative cues about what protagonists (and, by extension, students) should do or not do, such cues mainly pertain to steps, actions, and decisions. Correct and incorrect steps are frequently specified, but right and wrong outcomes are rarely articulated. ${ }^{13}$ Thus, notes remain relatively silent on the overall direction of the path traveled by protagonists; moral relativism easily settles in.

Cases are by far the most conspicuous organizational artifacts from students' vantage point. Teaching notes are a less visible, accompanying support of the cases and, more broadly, of the School's educational infrastructure. (First-year courses also include occasional exercises and group projects, but case-based teaching remains the norm.) The program of study proposed in the notes is one in which teaching and learning, and knowledge in general, is organized in purposeful ways. Notes therefore structure faculty members' teaching task in ways that are extremely consequential. When adhered to, teaching notes create a framework in which learning is discovered and constructed. More specifically, notes avoid stabilizing, at least in writing, any given normative view. Thus, the adherence to moral silence as a way to promote moral relativism seems to constitute a strong framework in the teaching notes used at the School. ${ }^{14}$

\footnotetext{
13. This analysis also holds for the ethical decisions in the "Leadership and Corporate Accountability" course. Some LCA teaching notes do, however, clearly spell out managers' legal responsibilities. For a discussion of managers' economic, legal, and ethical responsibilities, see Paine, Instructor's Guide.

${ }^{14}$ Some readers might hypothesize that students draw moral lessons at the School outside class discussions. This is, of course, true, yet other data sources (besides the teaching notes) also point to moral relativism as a guiding principle on campus. For more details on these data, see Anteby (2013).
} 


\section{From Teaching Tasks to Business Morals}

Teaching notes assist in the enterprise of recoding human problems as business challenges and of emphasizing the individual capacity to succeed or fail at solving such challenges. The individual trope is omnipresent in these notes. Individual accountability seems therefore emphasized throughout the structuring of faculty's work, and students' education. Yet by embedding this individual agency in a context where many, if not almost all paths, are deemed morally appropriate, the comparative assessment of the direction of distinct paths of actions proves more problematic. Indeed, notes remain fairly silent on the direction of such a course of action. Thus, the definition of proper conduct (within the realm of legality permitted behavior) remains quite amorphous. Though teaching notes typically articulate discrete business challenges, they mostly refrain from spelling out a broader goal. Notes' apparent silence on key normative issues allows for a variety of moral goals to coexist within the confines of the School.

The idea that the structuring of business school faculty members' teaching tasks might illuminate the cultural construction of business morality can seem, at first, far-fetched. Yet this article suggests that such an idea should be taken seriously. Identifying larger trends in smaller decisions or linking micro-practices to macro-trends offers a powerful lens into collective cultural constructions (Vaughan, 2002). Assuming such constructions are the result of an aggregation of a multitude of individual decisions, the examination of small moments in which tasks get performed is perhaps the only way to fully grasp larger trends.

The structuring of teaching tasks via the use of teaching notes can be consequential. Most School junior faculty members initially learn to tech by relying on them and thousands of other instructors purchase them to gain insights on how to teach in their classrooms. The moral 
relativism that ensues from promoting silence with respect to possibly competing normative viewpoints constitutes an ideology—one whose ancillary outcome lies in its ability to make it difficult to critically revisit executives' moral accountability. Unless steps are taken to restructure business school faculty members' teaching tasks, this ideology of silence will continue to shape and dominate the landscape of elite U.S. business education and beyond. A main benefit of this ideology is to welcome many moralities, but a main downside of it is also to allow for very few moral limits to be enforced. Thus, the puzzle of specifying the contents of business morals can also be in part answered by examining the discrete teaching tasks that get repeated day after day by faculty members with cohorts of hundreds of MBA students.

While an educational model that relies on silence to promote moral relativism might seem at first like a non-dogmatic model, it is important to recognize that a non-choice also is a choice (see Dworkin, 1996). The moral relativism resulting from enforcing relative moral silence constitutes an ideological standpoint that repeatedly encourages members to respect almost all moral viewpoints by enforcing a code of conduct built on silence. Implicitly, such a model also primes members not to vilify any moral viewpoint as long as it is presented as the result of an individual's choice. In such a context, a broadening of one's understanding of possible moralities is achieved, but at a significant price: almost anything can now be labeled "moral" and thus nothing can be deemed "immoral." It comes as little surprise that in a world where immorality cannot exist, few can be held morally accountable.

A key reason for why holding business leaders morally accountable might prove so difficult can partly be explained by these sounds of silence in business school education. If all moral viewpoints need to be respected and none proves higher than the next, then business leaders' actions can simply be constructed as one view among many others and the result of a 
chosen path of action. The decisions taken by General Motors' or Lehman Brothers' leaders might not be the one we would have chosen, but are ones that make sense in their (relative) moral worlds. Such moral relativism can easily allow amorality to thrive. The decisions not to recall faulty vehicles or to engage in creative accounting become one of a multitude of potential moral paths. Without a clear understanding of how organizational silence can act as a socialization mechanism to promote moral relativism, our understanding of business morals will at best remain coarse, if not misguided. 
Table 1: Sampled Teaching Notes Overview, 2007-2008

\begin{tabular}{lcccc}
\hline Course & Number of Cases & Number of Notes & $\begin{array}{c}\text { Percentages of } \\
\text { Cases with } \\
\text { Accompanying } \\
\text { Notes (\%) }\end{array}$ & $\begin{array}{c}\text { Number of } \\
\text { Sampled Notes }\end{array}$ \\
\hline Course A & 38 & 17 & 45 & 6 \\
Course B & 33 & 21 & 64 & 7 \\
Course C & 20 & 13 & 65 & 4 \\
Course D & 19 & 11 & 58 & 8 \\
Course E & 29 & 25 & 73 & 6 \\
Course F & 26 & 19 & 62 & 5 \\
Course G & 26 & 16 & 74 & 8 \\
Course H & 31 & 23 & 69 & 7 \\
\hline Course I & 29 & 20 & 73 & 6 \\
\hline Course J & 26 & 19 & 66 & 61 \\
\hline
\end{tabular}

Note: All ten required courses offered during the 2007-2008 academic year (e.g., finance 1, finance 2, marketing, technology and operations, strategy) are analyzed. A short-lived course on negotiation, also offered that year and since dropped from the curriculum, is excluded. A few simulations and alternate course materials (e.g., readings) are not included here. 


\section{References}

Abend, G. (2013). The origins of business ethics in American universities, 1902-1936. Business Ethics Quarterly, 23(2), 171-205.

Abend, G. (2014). Moral Background: An Inquiry into the History of Business Ethics. Princeton, NJ: Princeton University Press.

Anteby, M. (2013). Manufacturing Morals: The Values of Silence in Business School Education. Chicago: University of Chicago Press.

Barley, S. R., \& Kunda, G. (2001). Bringing work back in. Organization Science, 12(1), 76-95.

Barnes, L. B., Christensen, C. R., \& Hansen, A. J. (1994). Teaching and the Case Method. Boston: Harvard Business School Press.

Benford, R. D., \& Snow, D. A. (2000). Framing processes and social movements: An overview and assessment. American Sociological Review, 26, 611-639.

Boltanski, L., \& Chiapello, E. (1999). Le Nouvel Esprit du Capitalisme. Paris: Gallimard.

Both, A. (2008). Les Managers et leurs discours. Anthropology de la rhéthorique managériale. Bordeaux: Presses Universitaires de Bordeaux.

Bugental, J. F. T. (1978). The silence of the sky. In A. G. Athos \& J. J. Gabarro (Eds.), Interpersonal Behavior: Communication and Understanding in Relationships (pp. 176185). Englewood Cliffs, NJ: Prentice-Hall.

Carlile, P. R. (2004). Using artifacts to interpret and negotiate knowledge across domains. In A. Rafaeli \& M. Pratt (Eds.), Artifacts and Organizations (pp. 101-118). Mahwah: Lawrence Erlbaum.

Christensen, C. R., Garvin, D. A., \& Sweet, A. (Eds.). (1991). Education for Judgment: The Artistry of Discussion Leadership. Boston, MA: Harvard Business School Press.

Cohen, L. E. (2013). Assembling jobs: A model of how tasks are bundled into and across jobs. Organization Science, 24(2), 432-454.

Cohen, M. D., \& Bacdayan, P. (1994). Organizational routines are stored as procedural memory: Evidence from a laboratory study. Organization Science, 5(4), 554-568.

Cruikshank, J. (1987). A Delicate Experiment: the Harvard Business School, 1908-1945. Boston: Harvard Business School Press.

Davis, G. F. (2009). Managed by the Markets: How Finance Re-shaped America. New York: Oxford University Press.

Donham, W. B. (1926). Report of the President and Treasurer of Harvard College 1924-25. Official Register of Harvard University, XXIII(2), 117-124.

Donham, W. B. (1927). The social significance of business, Harvard Business Review, 4(4), 406419.

Dworkin, R. (1996). Objectivity and truth: You'd better believe it, Philosophy and Public Affairs, 25(2), 87-139. 
Eisinger, J. (2014, May 4). Why Only One Top Banker Went to Jail for the Financial Crisis. New York Times Magazine.

Elias, N. (1983). The Court Society. New York: Pantheon Books.

Elias, N. (2000). The Civilizing Process: Sociogenetic and Psychogenetic Investigations. Oxford, UK: Blackwell.

Fine, G. (1984). Negotiated orders and organizational cultures. Annual Review of Sociology, 10, 239-262.

Gehman, J., Treviño, L. K., \& Garud, R. (2013). Values work: A process study of the emergence and performance of organizational values practices. Academy of Management Journal, $56(1), 84-112$.

Ghaziani, A., \& Baldassarri, D. (2011). Cultural anchors and the organization of differences: A Multi-method analysis of LGBT marches on Washington. American Sociological Review, 76(2), 179-206.

Ghoshal, S. (2005). Bad management theories are destroying good management practices. Academy of Management Learning \& Education, 4(1), 75-91.

Glaser, B., \& Strauss, A. L. (1967). The Discovery of Grounded Theory. Chicago: Aldine.

Goffman, E. (1974). Frame Analysis: An Essay on the Organization of Experience. Cambridge, MA: Harvard University Press.

Gragg, C. I. (1940). Because Wisdom Can't be Told (HBSP Case 9-451-005). Cambridge: President and Fellows of Harvard College.

Hallett, T., \& Ventresca, M. J. (2006). Inhabited institutions: Social interactions and organizational forms in Gouldner's Patterns of Industrial Bureaucracy. Theory and Society, 35(2), 213-236.

Ho, K. (2009). Liquidated: An Ethnography of Wall Street. Durham, NC: Duke University Press.

Jackall, R. (1988). Moral Mazes: The World of Corporate Managers. New York: Oxford University Press.

Khurana, R. (2007). From Higher Aims to Hired Hands: The Social Transformation of American Business Schools and the Unfulfilled Promise of Management as a Profession. Princeton: Princeton University Press.

Lamont, M. (2010). The Return of the moral. In S. Hitlin \& S. Vaisey (Eds.), Handbook of the Sociology of Morality (pp. v-iix). New York: Springer.

Leidner, R. (1993). Fast Food, Fast Talk: Service Work and the Routinization of Everyday Life. Berkeley: University of California Press.

Margolis, J. D. (2001). Responsibility in organizational context. Business Ethics Quarterly 11(4), 431-454.

Margolis, J. D., \& Walsh, J. P. (2003). Misery loves companies: Rethinking social initiatives by business. Administrative Science Quarterly, 48, 268-305.

McArthur, J. H. (1985). Foreword. In J. W. Pratt \& R. J. Zeckhauser (Eds.), Principals and agents: The Structure of business (pp. vii-viii). Boston: Harvard Business School Press. 
Morrill, C. (1991). Conflict management, honor, and organizational change. American Journal of Sociology, 97(3), 585-621.

Morrison, E. W., \& Milliken, F. J. (2000). Organizational silence: A Barrier to change and development in a pluralistic world. Academy of Management Review, 25(4), 706-725.

Newman, K. S. (1988). Falling from Grace: Downward Mobility in the Age of Affluence. Berkeley: University of California Press.

Orth, C. D. (1963). Social Structure and Learning Climate: The First Year at the Harvard Business School. Boston: Division of Research, Graduate School of Business Administration, Harvard University.

Paine, L. S. (2006). Instructor's Guide to Leadership and Corporate Accountability (LCA) (HBSP Note 5-307-032). Cambridge: President and Fellows of Harvard College.

Parkhurst Ferguson, P. (2004). Accounting for Taste: The Triumph of French Cuisine. Chicago: University Of Chicago Press.

Perrow, C. (2002). Organizing America: Wealth, Power, and the Origins of Corporate Capitalism. Princeton: Princeton University Press.

Petriglieri, G., \& Petriglieri, J. L. (2010). Identity workspaces: The case of business schools. Academy of Management Learning and Education, 9(1), 44-60.

Piper, T. R., Gentile, M. C., \& Parks, S. D. (1993). Can Ethics be Taught? Perspectives, Challenges, and Approaches at Harvard Business School. Boston: Harvard Business School Press.

Ruef, M. (2008). Review of From Higher Aims to Hired Hands: The Social Transformation of American Business Schools and the Unfulfilled Promise of Management as a Profession, Administrative Science Quarterly, 53(4), 745-752.

Ruef, M. (2010). The Entrepreneurial Group: Social Identities, Relations, and Collective Action. Princeton: Princeton University Press.

Schleef, D. J. (2006). Managing Elites: Professional Socialization in Law and Business Schools. Lantham, MD: Rowman \& Littefield.

Sucher, S. J. (2011). Action Planning: An LCA Perspective. Harvard Business School Module HBS Note 605-079. Boston: Presidents and Fellows of Harvard College.

Sucher, S. J., \& Hsieh, N.-h. (2011). A Framework for Ethical Reasoning." HBS Note 610-050. Boston: Presidents and Fellows of Harvard College.

Vaughan, D. (2002). Signals and interpretive work: The role of culture in a theory of practical action. In K. A. Cerulo (Ed.), Culture in Mind: Toward a Sociology of Culture and Cognition (pp. 28-54). New York: Routlege.

Zelizer, V. A. (1979). Morals and Markets. The Development of Life Insurance in the United States. New York: Columbia University Press. 